\title{
The Design of a Sustainable Competency-Based Human Resources Management : A Holistic Approach
}

\author{
Fanny Klett* \\ Business Area Data Representation and Interfaces \\ Fraunhofer Institute Digital Media Technology \\ 98693 Ilmenau, Germany \\ E-mail: fanny.klett@idmt.fraunhofer.de
}

*Corresponding author

\begin{abstract}
Human capital is a key source of innovation and competitive improvement. Exploiting its potential and boosting its value to the organization involves a systematic process to determine the competencies that are fundamental to achieve enhanced job performance. However, why do organizations often fail to successfully cope with the main challenges of the knowledge and learning society, and to identify the consequences for learning technologies? This paper discusses a holistic model for human resources management strategy required to technologically support the organization toward a forceful and comprehensive solution. By applying a step-wise approach, the components that organizations should consider are identified, along with their interrelationships, and the increased need for a harmonizing world-wide standardization in this application field.
\end{abstract}

Keywords: Learning Technology, Competency Management, Assessment, Quality Management.

Biographical notes: Fanny Klett (Ph.D.) leads the Data Representation and Interfaces Business Area at the Fraunhofer Institute for Digital Media Technology. She assumed the Directorship of the German Workforce ADL Partnership Lab in 2009. Dr. Klett's interests focus on synergies between distributed learning and training, and applied research and development in the fields of information and content management, digital libraries as well as competency and performance management. She serves as a Principal Investigator and Coordinator on $\mathrm{R} \& \mathrm{D}$ projects that are funded by various programs of the European Commission and the German government.

Dr. Klett actively works on the IEEE Learning Technology Standards Committee and in ISO JTC 1/SC 36, Information Technology for Learning, Education and Training. She has published over 60 technical papers and book chapters, and was awarded patents in the area of educational technology. Dr. Klett is an associate editor of the IEEE Education Society and ASEE Electrical and Computer Engineering Division joint publication "The Interface", serves on the review boards of the IEEE Transactions on Education and the IEEE Educational Technology and Society Journal as well as being a peer-reviewer for the European Commission R\&D Program.

Dr. Klett is IEEE Fellow and chairs committees on the IEEE Educational Activities Board and the IEEE Computer Society Member and Geographic Activities Board as well as the German Chapter of the IEEE Education Society. She is also Member of the Council and the Academic Board of the European Association for Education in Electrical and Information Engineering. 


\section{Introduction}

Rising competition obliges companies to seek for innovative ways of doing business, increase effectiveness and efficiency of work, and productivity. Information and Communication Technologies (ICT) help business achieve these aims whereas the pressure to keep on innovation grows. Human capital is a key source of innovation and competitive improvement. Thus, talent and learning appear to become essential business aspects of innovation and competitive advantage. Exploiting the potential of the human capital and boosting its value to the organization involves a systematic process to determine the key factors that concern the organization, and the individual. These factors are the competencies that are fundamental to achieve enhanced job performance (organizational factor), and conversely, the knowledge, skills, attitudes and behaviors compulsory for a person to carry out a particular job in an outstanding manner (individual factor).

So, why do organizations often fail to successfully cope with the main challenges of the knowledge and learning society, and to identify the consequences for learning and competency technologies?

In this paper, this question is examined through the analysis of a multi-component architecture for a sustainable competency-based human resources system.

The Human Resource Services Report (PricewaterhouseCoopers, 2006) undoubtedly demonstrates that clear correlations exist between high investment in learning and competitive business results. Applying competencies represents a driving force for outlining the future performance potential and integrating processes into challenging Human Resource Management Systems. The management of talent and learning can only be achieved through the alignment of strategy, learning and technology.

Viewed this way, an alignment between managing learning, ability and performance is needed, in order to set long term development goals for both, the organizations and the employees. The identification of gaps and the required development of skills enable organizations to suitably work out development plans whereas employees follow achievable career paths. Therefore, such organizations that commit to talent management and learning, and decide to track, identify and process competencies and skills, can achieve a variety of business advantages such as transparency about the expectations of employees and managers; development of a common language in the case of distributed and global organizations, in order to effectively communicate among multiple locations as well as implementation of consistent standards across the organization.

Seen in light of the strategic management point of view, the problem is to identify the human resources development strategy to continuously maximize the competitive advantage based on the company's unique culture, capabilities and business objectives. Many outstanding organizations have provided an extensive research and field testing in this domain. But there is still need on observing and exploring a wide range of aspects to be able to provide cutting edge professionally designed human resources programs and systems. Unfortunately, strategic management research has commonly not reflected individual competencies. Mostly, human resources management (HRM) is related to aligning the strategic objectives with the development of the workforce. 
Established HRM methods such as job analysis, training, and career development plans often omit the consideration of strategic objectives. Further, one of the main obstacles of recent HRM programs is the low use of the opportunities provided by innovative ICT, especially web-based technologies. The strategic use of ICT requires the responsibility of individuals toward developing their skills to benefit from new career and learning opportunities, and of enterprises toward recognizing the challenges of the knowledge society, responding to changes in the environment and the society, and properly implementing change management. Also current research undoubtedly demonstrates that recent HRM methods unsatisfactorily provide the opportunities needed to enhance the productivity of the knowledge workers to shape the productivity challenge in the knowledge-based economy (Elkjaer, 2000). Especially, the problems arise due to the missing cooperation and collaboration options, which serve as a basis for the enhancement of the growing multinational and international businesses. Further widely neglected issues concern systems' interoperability, standardization and missing harmonization between standards.

Against this background, it is strongly required to implement a competency-based approach to the human resources development to help ensure a successful deployment of a workforce enhancement, and support business growth strategies by strongly considering recent standardization efforts.

The remainder of this article is organized as follows. Section 2 briefly describes the terminology applied. Section 3 examines the impact of performance management in terms of HRM, the problems identified, and briefly introduces recent standardization efforts. Section 4 then explains the main components of a general framework for a competency-based HRM system. Finally, Section 5 concludes the article with a potential future research.

\section{Description of Terminology}

Frequently, it has been argued that the success of modern businesses depends more on the intellectual assets, such as implicit and explicit knowledge, of the workforce than on the tangible business resources (Stewart, 1997, Sveiby, 1997). The intellectual assets incorporate knowledge and skills, and it is quite often excluded of consideration that these assets involve also attitudes and behaviors. By integrating knowledge, skills, attitudes and behaviors to a new operational element, we introduce the term competency.

Competency refers to any aspect of a competence, such as knowledge, skill, attitude, ability, or learning objective. The term "competency" is to be interpreted in the broadest sense to include learning objectives - those things that are sought - as well as competencies - those things that are achieved (IEEE Std. 1484.20.1TM, 2007).

According to IEEE Std. 1484.20.1TM (2007) and Ostyn (2006), this paper uses the term "competency" in preference to "competence" due to its frequent use in educational and training contexts in association with performance ability for specific tasks and roles, on the one hand, and its incorporated structured granularity with the opportunity to be assessed and measured, and the holistic scheme of the term "competence" that makes it difficult to be formalized in operational terms, on the other hand.

Competitive performance in today's organization requires a sufficient consideration of the acquisition, recognition and use of competencies within the organizations. Performance - the ability of the employees to achieve the business 
objectives of the enterprise - is a constantly raising factor in each business. Thus, there is an increased business and social requirement for capturing, storing, exchanging, and managing competencies.

In the past, the term "assessment" was used to refer particularly to the process of determining the extent to which learners have mastered a subject. On the one hand, it is critical for measuring the employee's achievement within the learning process. Thus, employees can understand to what extend learning objectives have been accomplished. On the other hand, it can also be used as a teaching tool to help employees better understand concepts and enhance their skills.

Assessment has recently been extended in the academic context to cover all uses of evaluation. Assessment data are observations or facts that must be collected, organized, and analyzed to become useful. The purpose of testing is to determine if learning objectives have been accomplished. Testing and performance tracking will remain an inseparable part of learning, and particularly of instructional design for traditional as well as web based education and training systems (Klett, 2008).

Performance assessment plays a fundamental role in evaluating the employee's knowledge acquisition and achievements. Employers commonly apply assessments to carry out job applicant selection and get measurement data related to the employee's motivation and development plans, and the general employee's development.

Concerning quality assessment, educational and training services, and teaching/learning evaluation need a clear distinction from monitoring organizational processes. Evidently, it is important to identify also the assessment demands of the pedagogical dimension that represents the basis for teaching and learning activities toward effective education and training. A holistic assessment environment is needed within which the programs or projects are operating, and which offers educators and trainers a better theory, principles, and pedagogy to build up their future teaching approaches, in order to advance the learning process, and to more effectively serve the organization (Klett \& Scholz, 2008).

By following this reflection on the terminology used, the next sections address the main building blocks that should be considered by designing an acceptable and sustainable HRM system in a competitive organization, their interrelationships and inseparable structure as well as the rising challenge for interoperability between those building blocks and incorporated systems.

\section{HRM and its Implications for Performance Management}

Performance management represents a holistic process that brings together all processes that effectively support and enlighten organizational goals, evaluate employee's performance and recognize employees credibly. Integrated performance management is an innovative process that provides both, a strategy and a process for building up human talent. It has to intertwine various aspects of business, and people management for both, individuals and teams.

Performance management concerns the establishment of a culture that allows individuals and groups to continuously advance business processes and their own competencies. Successful performance and talent management can improve the employee's self-confidence and overall productivity. It can assure quality management 
processes and lead to competitive advantages. It is evident that motivated and valued employees are essential to any company.

Performance management counts as a ubiquitous process. Generally, it provides a framework for people's activity and the facilitation of this operation. This framework contains competency management, learning, assessment and quality aspects as shown in Figure 1. The components of this framework will be in the focus of the following subsections.

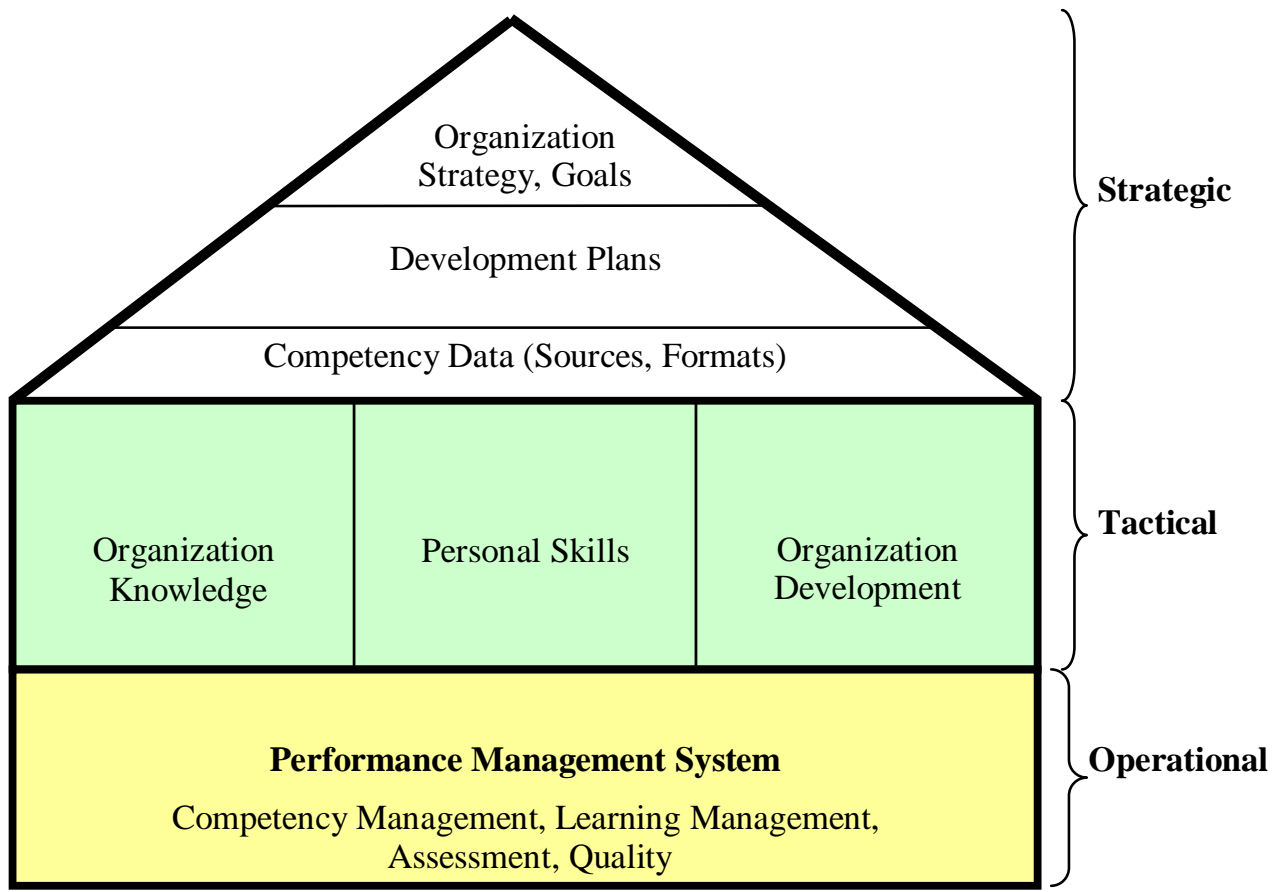

Figure 1. Holistic view on the performance management process in an organization

\subsection{Competency Management}

Competency management involves the measurement of and the judgment on the competencies of all employees, in order to determine proper career development plans according to the company's business objectives. It refers to all methods applied in an organization to

1. systematically consider current competencies;

2. identify gaps between job descriptions and those competencies;

3. analyze learning gaps;

4. determine important aspects for the development plan to achieve the future competencies necessary for the job tasks to be performed;

5. detect redundancy; 
6. achieve awareness of available competencies for the preparation of new assignments, tasks and projects.

Thus, competency management appears to be related to HRM, and strategic management, on the one hand, and to assessment, on the other hand. While the strategic management addresses the identification of the human resources development strategy to continuously maximize the competitive advantage based on the company's unique culture, capabilities and business objectives, HRM is typically related to harmonizing the company's strategic objectives with the development of the workforce. In order to track the human development, each organization needs to define and map a certain model that reflects the agreed HRM program for strategic areas such as recruitment, skill gap analysis, career development plans, training efforts, self-organized learning, and learning management, self-assessment, mobility, etc.

Essential components that organizations should consider in the course of implementing a technology-based competency management system concern firstly the implementation of a successful strategic management scheme that addresses the definition of organizational goals, and the assurance that these goals are intertwined with individual goals. An analysis of available data to ensure the properness of those goals is required. Further, a systematic consideration of competency data for every employee is needed. These competency data may have various sources and may exist in different formats. Additionally, recruitment and hiring procedures, project management procedures, skill gap analysis, personal development plans, self-organized learning, and learning management in both, an enterprise context, and possibly an academic context, are in the focus of this process.

The implementation of technology-based competency management and assessment in the framework of performance support, training and adaptive web-based learning undoubtedly serves and supports personal development. Thus, for prosperous organizations, it is important to apply competency and skill development to ensure an accurate salary culture. Accordingly, employees in such organizations can experience the respect of the organization.

The key aspects of technology-based competency management involve:

1. the definition of long term personal development goals;

2. the definition of learning objectives to acquire competency;

3. the ability to record, map and keep track of competencies.

\subsection{Learning Management}

Despite great expectations, significant effort and even more extensive investment and expenditure, the use of ICT for learning leading to knowledge development for learners and organizations remains problematic. Contemporary e-learning systems present some significant productivity and effectiveness advantages over traditional teaching and training methods. ICT appears to have the potential to individualize learning and to provide it independent of time and location, improving its quality and efficiency in many aspects such as exploration, communication, multiple representations, and multiple dimensions (time, space, distributed knowledge).

Currently, there are three primary sets of technologies that can provide an infrastructure framework for delivering the complete suite of e-learning services: Virtual Classroom, Learning Management System (LMS), and Learning Content Management System (LCMS). Commonly, these technologies support an interface to organizationintern user databases such as LDAP. 
LCMS are regarded as a significant contemporary approach for virtual learning. These virtual learning spaces provide a means for the organization, administration and support of web-based teaching and learning processes that are potentially optimum in terms of location and time of individual learning. Their key advantage is resource management on a learning object approach (IEEE 1484.12.1, 2002) compared to LMS where the resource management is based on a course/module basis. The benefits of the learning object approach are seen as follows (Farance, 2000):

1. Repurposing: Content in learning object format can be more readily reused for different purposes and can be easily updated by replacing only outdated learning objects content rather than having to rebuild a new course.

2. Personalized learning: Customized learning can be produced to meet individual and specific needs.

3. Performance support capabilities: Learners are able to locate specific information they need from learning objects in the context of their work.

4. Distributed authoring: Subject matter experts can author new learning content directly.

Recently, there is a need to shift the emphasis on more cognitive and usability questions as e-learning systems provide static human computer interfaces (Klett, 2005). This trend requires a new analysis of information and knowledge treatment in order to facilitate creating an active learning situation and to support exploratory activities. The recent level of adaptation is limited usually to aspects of the user interfaces. In particular, contemporary systems:

1. do not satisfactorily explore and use multi-sensory input;

2. do not recognize and adapt to the emotional and physical state of the individual learner at various learning phases;

3. lack the direct contact between the learner and the tutor;

4. do not properly consider a trusted environment.

The scientific approach of future developments must be related to a broad interdisciplinary work driven by "learning pull" rather than "technology push". A methodical and dynamic infrastructure that concerns a learning system as a personalized role-based place being in the same time configurable according to individual and institutional needs, and regulatory requirements, is still missing. Thus, high-level adaptation requirements are rising.

Within the wider vision of e-learning as a contribution to knowledge management or knowledge development - at all its different stages and in all its different forms - a common model for e-learning and e-knowledge architecture is required to allow the users obtain instant satisfaction and push the organization toward a forceful and comprehensive knowledge management system, in a step-wise approach.

The next subsection reflects on key aspects, which concern quality management of the training and learning services as a part of the global framework for a strategic competency development in an organization. Quality management is also related to the assessment process. 


\subsection{Assessment and Quality Management}

In general, competency management has a long successful story in the USA. Schippman et.al. (2000) summarize that " $75-80 \%$ of responding companies have some competencydriven application in place“. However, web-based competency management is applied typically mainly toward web-based assessment.

Recently, integrated web-based assessments facilitate the processes of proper position filling and team building. Taking reliable decisions on selecting the right people at the right time for the right task can significantly affect the organizational change. Web-based assessment primarily requires:

1. high level of interaction, in order to map various question types such as open, semi-open and closed question types (multiple choice, ordering tasks, fill-in-the-blank tasks, etc.) onto the user interface;

2. secure and controlled access to the content;

3. reusability and interoperability of the content;

4. tracking the learner, monitoring and processing his/her answers;

5. assessing the results and generating statistical data.

Exchange and sharing of test items between assessment systems or databases is a vital element to reduce company's costs and improve the interoperability between various organization-wide systems such as HRM, learning management, authoring, assessment, delivery systems, or test item banks, etc. Thus, the following elements of the web-based assessment appear to become crucial:

1. the use of a uniform exchange format based on XML to facilitate the interoperability and allow for sharing of structured data across systems, and tracking the progress of the employees who take part in the assessment;

2. the provision of feedback and hints to encourage and motivate these employees;

3. the adaptation to the individual knowledge of the employees, which requires the availability of numerous test items attached to a particular subject to serve the comprehensive test of the employee's knowledge.

4. metadata description of both, the test items, and the test compositions, to enable reusability, and interoperability between human resources management, learning management, authoring, assessment, delivery systems, or test item banks.

Quality management concerns the organizational part of educational and training services, and its purpose is to ensure the evaluation of their impact. There is a rising social requirement to implement quality management approaches in instructional systems for traditional as well as web-based education and training. Thus, over the past years, the selection criteria for educational services and vocational training programs toward receiving governmental support have been strengthened. In addition, the need for quality management rapidly grows up as the heterogeneity of training institutions results in a variety of interests, goals, and contents of teaching and learning. Economic competition and employability increasingly raise the demand for implementation, maintenance and audit of quality criteria for educational and training services. 
The DVWO ${ }^{1}$ Quality Model represents a generic quality management approach that was designed to support the implementation and maintenance of quality criteria for learning and training services, and to ensure the evaluation of their impact. This model is deployed in instructional systems for traditional as well as web-based education and training and can serve as a framework also for a $360^{\circ}$ view of assessment and quality management for learning and training systems.

The terms of reference of the DVWO Quality Model conform to the international standard ISO 9001 and the German Approval and Accreditation By-law - Vocational training $^{2}$ (AZWV) specifications. It is aligned with the contents of educational activities by using special taxonomies in cognitive (intellectual capability), affective (feelings, emotions and behavior), and psycho-motor (manual and physical skills) domains (Möller, 1976, Anderson \& Krathwohl, 2001) as well as a self-adjusting domain (according to individual requirements of the organization).

By applying this structure, the DVWO Quality Model corresponds to the requirements of the European Qualification Framework (EQF). Interested parties can be independently audited and certified that their educational and training services meet the standards set by ISO 9001, and the approval criteria of the AZWV. While the organizational and administrative processes can transparently be documented on the basis of ISO 9001, the DVWO Quality Model bonds also the interrelated and interacting learning and training processes. Thus, the use of the DVWO norms sets a focus on the employee's demands and puts the pedagogical dimension in the centre of the evaluation.

In addition to the eight ISO 9001 quality management principles, the DVWO Quality Model points four further principles out:

1. The educational services must be structured on the basis of the DVWO Quality Model.

2. Quality criteria must be classified using the Competencies Pyramid in conjunction with the Content Objective Matrix.

3. Curricula can be arranged in an open or closed manner. The open curricula require the completion of the operational objectives according to Mager (1962).

4. Training services must be evaluated.

The Competencies Pyramid and the Content Objective Matrix represent tools to construct objectives for learning and training programs, and set the required measurement criteria for the training outcomes - a process, which is necessary for the evaluation. Each level of the Competencies Pyramid defines a state of a learning experience. It is a hierarchical construct to subsume that participants have to master each level before progressing to the next level. In order to advance to the next level of the pyramid, the employee has to visit the previous learning level (Klett \& Scholz, 2008).

As illustrated in Table 1, the Content Objective Matrix of the DVWO Quality Model involves the following components:

1 DVWO: German Training Association (German: Dachverband der Weiterbildungsorganisationen e.V.)

2 AZWV: Approval and Accreditation By-law - Vocational training (German: Anerkennungs- und Zulassungsverordnung Weiterbildung) 
Table 1. Content Objective Matrix

\begin{tabular}{|l|l|l|l|}
\hline $\begin{array}{l}\text { Content } \\
\text { (what) }\end{array}$ & $\begin{array}{l}\text { Teaching } \\
\text { (who) }\end{array}$ & $\begin{array}{l}\text { Learning } \\
\text { (how) }\end{array}$ & $\begin{array}{l}\text { Transfer } \\
\text { (for what) }\end{array}$ \\
\hline $\begin{array}{l}\text { Learning content } \\
\text { shaped toward the } \\
\text { employers'/customers' } \\
\text { expectations }\end{array}$ & $\begin{array}{l}\text { Instructors' } \\
\text { qualifications } \\
\text { identified by the use } \\
\text { of the Competencies } \\
\text { Pyramid }\end{array}$ & $\begin{array}{l}\text { Learning objectives } \\
\text { identified by the use } \\
\text { of the Competencies } \\
\text { Pyramid }\end{array}$ & $\begin{array}{l}\text { Recognition of } \\
\text { learning outcomes } \\
\text { identified by the use } \\
\text { of the Competencies } \\
\text { Pyramid }\end{array}$ \\
\hline $\begin{array}{l}\text { Competency level } \\
\text { (example) }\end{array}$ & 6 & 5 & 4 \\
\hline
\end{tabular}

Figure 2 shows the possible interrelationship between the competency levels of the instructor, the employee/trainee, and the outcome for the employee or employer/customer.

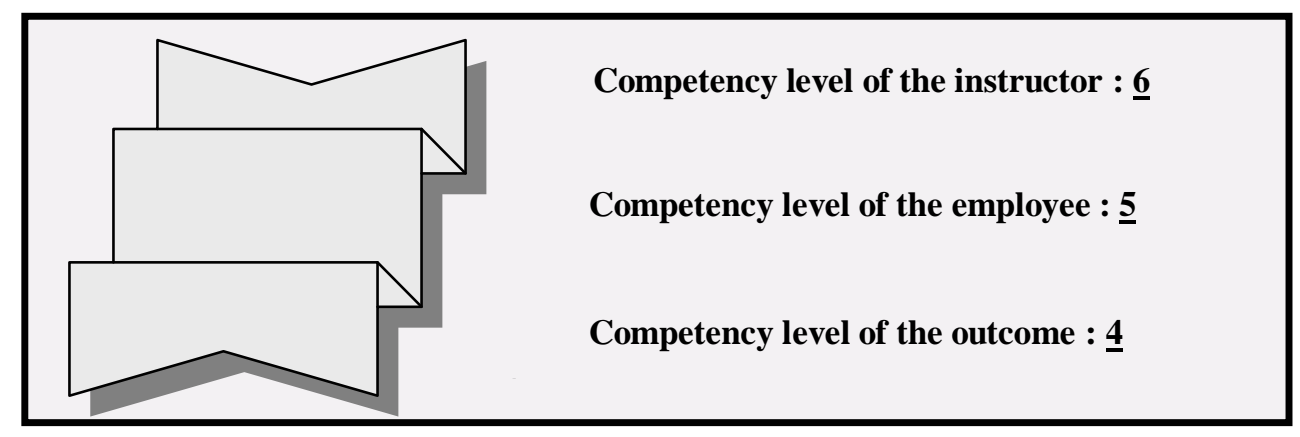

Figure 2. An example of an interrelationship between the competency levels of the instructor, the employee, and the outcome

The DVWO Quality Model is able to facilitate the transfer, transparency and recognition of learning outcomes assessed by self-evaluation, or certified by expert centres as well as ISO 9001 certification institutions. It can also encompass detailed descriptions of particular qualifications, learning pathways or evaluate training conditions.

\subsection{The Identified Problems and Ongoing Standardization Efforts}

Strategic and performance management systems are difficult to be implemented. The main concerns result from intellectual property issues, and control in the organization. Conversely, if such systems are implemented they undoubtedly serve and support personal development, although performance rating may cause opposition. Problems arise when components and user interfaces lead to a cognitive overload by the employees, especially when there is a missing understanding of goals and how they can be achieved on both, the individual, and the organizational level (Klett, 2008).

The keys to the successful introduction and application of performance management are: 
1. clearly define the means of performance in the particular organization;

2. clearly set the rules for performance management in the organization;

3. strongly set a focus on the individual employee's development plan and his/her benefits from taking part in the organizational advance.

Various problems arise when human resources related systems are not able to support interoperability of skills and competency data. According to (Hirata \& Brown, 2008) typical problems concern:

1. Human resources information cannot be shared within different HRM platforms.

2. Human resources information cannot be used within human resources development easily because it usually does not deal with detailed skills and competency information.

3. Individual status of ownership level and proficiency about skills and competency could not be dealt within recent HRM systems.

4. Individual developmental paths cannot be dealt within recent HRM systems.

5. Individuals and organizations cannot design a career strategy and a career path on a common basis by using HRM systems.

6. Skills and competency have to become interoperable entities.

7. Assessment requires objectivity by the support of adequate systems.

8. HRM systems cannot substitute human assessment for an everyday work performance.

Against this background, organizations have increasingly to deal with a complex and strongly intertwined strategic management structure. Various problems arise when HRM systems are not able to support interoperability of competency and assessment data. Along with these facts, many exciting new learning and training technologies exist, but their application has often been lacking coherence and their uptake unacceptably delayed. Nowadays, significant difficulties exist to cover learning and education improvements worldwide - mostly, because content and systems are not interoperable throughout the world businesses.

As a result, learning and competency standards move into the focus of recent developments. Currently most HRM stakeholders have a vague notion of their existence and utility. Standards make learning and competency technologies interoperate in a global network. They contribute to factors such as interoperability, portability and scalability of the systems.

Within the last ten years, some industrial and other organizations have been developing information technology standards in the HRM domain, e.g. IEEE LTSC, IMS Global Learning Consortium, HR-XML Consortium, and ISO/IEC JTC1 (IEEE 1484.20.1, 2007, IMS Reusable Definition of Competency or Educational Objective Information Model, 2002, HR-XML Consortium, 2010). These independent standards are similar and their relationships are confusing.

The IMS Global Learning Consortium released in October 2002 a specification for Reusable Definition of Competency or Educational Objective (RDCEO), which 
contains an information model, a best practices document and an XML binding (IMS Reusable Definition of Competency or Educational Objective - Information Model, 2002).

These documents built the foundation for an IEEE LTSC project that led to the IEEE Standard for Learning Technology - Data Model for Reusable Competency Definitions (IEEE 1484.20.1, 2007). This standard defines a data model for describing, referencing, and sharing competency definitions, primarily in the context of online and distributed learning. It provides a way to represent formally the key characteristics of a competency, independently of its use in any particular context. In addition, it enables interoperability among learning or other systems that deal with competency information by providing a means for them to refer to common definitions with common meanings.

By providing a clear interface between the components involved in a strategic and performance management system, ongoing learning, competency and performance technology standards will allow for an independent and rapid improvement of the components involved, leading to competition in industry as well as collaboration between various stakeholders. Then, the embedded standardization mechanism will become a source of innovation in this promising area.

The next section summarizes the main components toward a general structure for a holistic competency-based HRM system.

\section{The General Framework for a Competency-Based HRM System}

Competitive performance in today's organization requires an adequate consideration of the acquisition, recognition and use of competencies within the organizations. Thus, there is an increased business and social requirement for capturing, storing, exchanging, and managing competencies.

Figure 3 illustrates the main components of a modern web-based strategic management structure by integrating all the important operational blocks explained in the previous section, and the technologies behind. Against this background, technologybased competency management should enable planning, classifying, mapping and implementation of specific personnel and organizational measures to achieve the professional development of the workforce.

Web-based competency management should enable the assignment of job descriptions and competency definitions to a particular position. It also should continuously allow for tracking the qualifications, competencies and certificates of the workforce. In parallel, the interoperability with learning management systems is desired, as they will take care of the gap analysis, the self-organized learning of the employee, the monitoring of the employee's progress, and the assessment results. In terms of providing learning opportunities, also learning content management based on interoperable and sharable content increases on importance.

Web-based competency management involves also the classification of competencies and their application domain, the proper management of the defined competency profiles, and possibly the exchange of competency definitions (descriptions). Mostly, competencies cover two types, behavioral and technical competencies. The behavioral competencies concern the 'soft' skills such as communication, creativity, and problem-solving. They can be mapped on various job tasks and functions in contrast to the technical competencies, which mostly appear to be unique for a certain job description. 


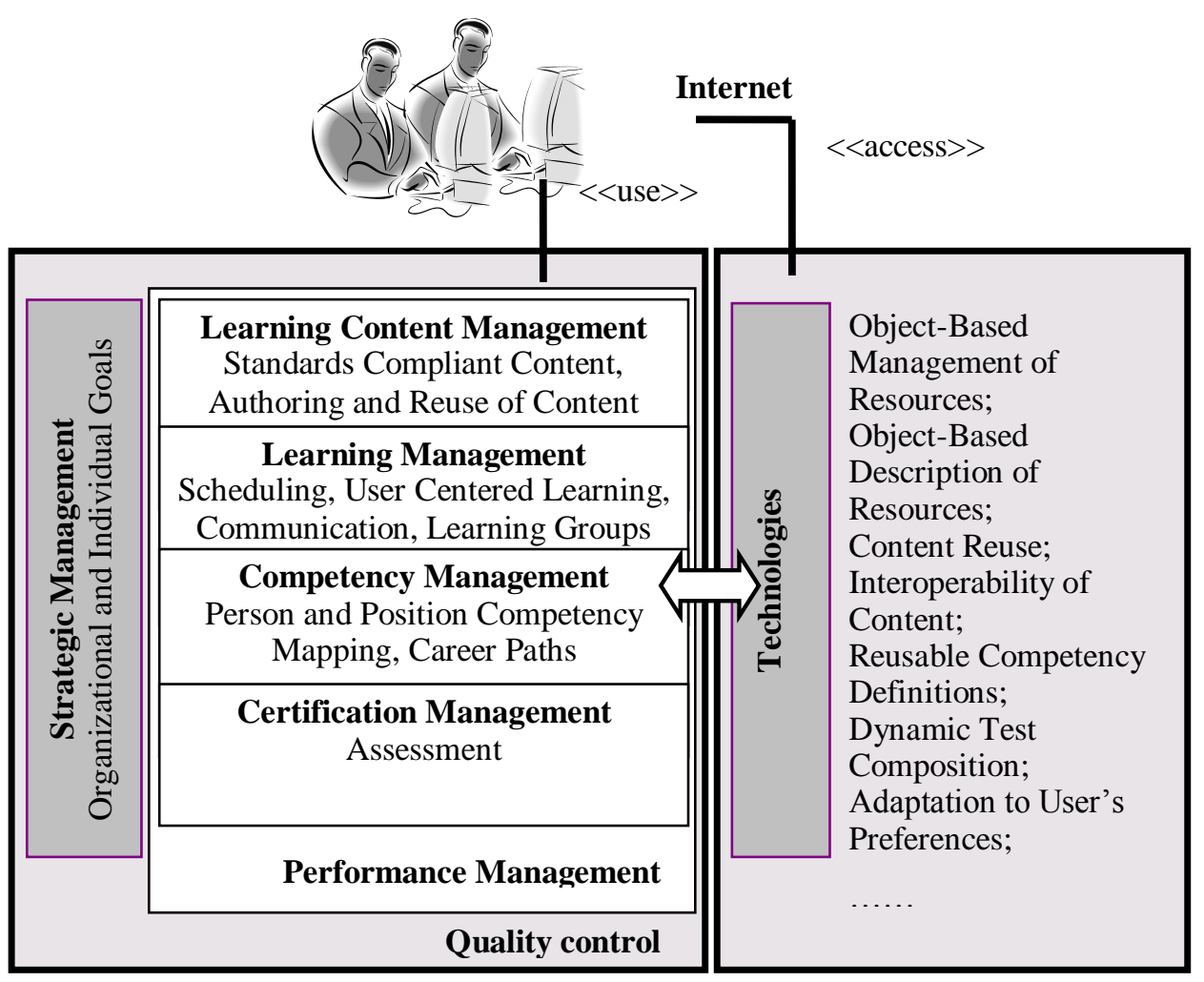

Figure 3. Main components of a sustainable holistic competency-based HRM structure

Summarizing, the keys to the successful introduction and application of competency management and assessment are:

1. comprehensible definition of organizational and individual goals in the means of job performance and company's competitive advantage;

2. comprehensible rules for competency management in the organization such as availability of a classifications catalogue, and fine granular job descriptions;

3. solid individual development plans with certification opportunities and quality control.

The precise evaluation of the organization's strategic management enables managers to identify areas to be improved, to design career development plans, and to evaluate development effectiveness against a well-defined set of metrics and goals. All these tasks belong to a higher definition sustainability based on quality management that concerns the organizational part of the company's services. Its purpose is to ensure the evaluation of the impact of those services. The tasks of the quality management regarding the educational and training services should be directly intertwined with the strategic management of the organization. 


\section{Conclusions}

This article analyzes a holistic framework for a sustainable HRM infrastructure based on quality management.

Many conclusions and approaches may not be applicable to every organization. As well, many implementations of the proposed holistic approach are possible. However, we have continuously to consider advanced technologies, and standards as a joint main driver for innovation. Quality management needs, skill and competency information technologies, standardized competency definitions and e-portfolios are in the scope of advanced technological development. Uptake of learning technology standards is increasing even if the existent standards are just starting to have their initial impact on institutions and on individual teaching faculty. Recently, various research and development projects deal with standards and their adoption. Unfortunately, currently most HRM stakeholders have a vague notion of the existence and utility of those technologies and standards.

However, standards make learning, training, performance and competency technologies interoperate in a global network. They contribute to factors such as portability and scalability of the systems. Thus, the potential for technology-based learning and training, and competency management will not remain just a vision.

Organizations that commit to talent management and learning, and decide to track, identify and process competencies and skills, can achieve transparency about the expectations of employees and managers. They can develop a common language in the case of distributed organizations to effectively communicate among multiple locations, and they can benefit from the adoption of consistent systems across the organization.

The hope is that widespread acceptance of learning and performance technologies and standards will foster shared resources among institutions and provide new efficiencies for HRM programs.

\section{References}

1 Anderson, L.W. \& Krathwohl, D. R. (Eds.). (2001). A Taxonomy for Learning, Teaching, and Assessing: A Revision of Bloom's Taxonomy of Educational Objectives. Longman, New York.

2 Elkjaer, B. (2000). Learning and getting to know: the case of knowledge workers. Human Resource Development International, 3(3), 343-359.

3 Farance, F. (2000). IEEE Learning Technology Standards Committee Work Program and Process. Presentation on an IEEE LTSC working meeting.

4 Hirata, K. \& Brown, M. (2008). Skill-competency management architecture, Proc. Workshop on Strategic Approach for e-Learning Standards: Design, Implementation and Application, 16th International Conference on Computers in Education, ICCE, Taipei.

5 HR-XML Consortium. Completed specifications (2010). [Online]. Available: http://www.hr-Xml.org/hr-xml/wms/hr-xml-1-org/index.php?id=\{1385974ED5904 A4386 16FF7BDB3F7439|140|2\}.

6 IEEE Standard for Learning Technology_Data Model for Reusable Competency Definitions, IEEE Std. 1484.20.1TM, 2007. 
7 IEEE Draft Standard for Learning Object Metadata, IEEE 1484.12.1 (2002). [Online]. Available: http://ltsc.ieee.org/wg12/20020612-Final-LOM-Draft.html.

8 IMS Reusable Definition of Competency or Educational Objective - Information Model, Version 1.0 Final Specification, (2002). [Online]. Available: http://www.imsglobal.org/competencies/index.html

9 Klett, F. (2005). The Challenge in Learning Design Concepts: Personalization and Adaptation in Virtual Arrangements. Proc. of 6th IEEE ITHET International Conference of Information Technologies Based Higher Education and Training, ITHET 05, Juan Dolio.

10 Klett, F. (2008). The rising challenge for assessment standardization in web based learning, education and training. Proc. Workshop on Strategic Approach for ELearning Standards: Design, Implementation and Application, 16th International Conference on Computers in Education, ICCE, Taipei.

11 Klett F. \& Scholz H. (2008). $360^{\circ}$ view of assessment and quality management. White paper SCORM 2.0 Workshop. [Online]. Available: http://www.letsi.org/letsi/display/nextscorm/360+View+of+Assessment+and+Quali ty+Management.pdf.

12 Mager, R. F. (1962). Preparing Instructional Objectives. Fearon Publishers, Palo Alto, California.

13 Möller, C. (1976). Technik der Lehrplanung. Beltz Verlag. Weinheim und Basel.

14 Ostyn, C. (2006). Service oriented architecture for competency-based lifelong learning and personal development. [Online] Available: http://www.ostyn.com/standardswork/competency/SOA-for-Competency.pdf.

15 PricewaterhouseCoopers Human Resource Services (2006). Key trends in human capital: A global perspective. [Online]. Available: http:// www.pwchk.com/webmedia/doc/633077569676719728 hra keytrends mar06.pdf.

16 Schippman, J. S., Ash, R. A., Battista, M., Car, L., Eyde, L. D., Hesketh, B., Kehoe, J., Pearlman, K., Prien, E. P. \& Sanchez, J. I. (2000). The practice of competency modeling. Personnel Psychology, 53(3), 703-740.

17 Stewart, T. A. (1997). Intellectual capital: the new wealth of organizations. Doubleday, New York.

18 Sveiby, K. E. (1997). The New Organizational Wealth. Berrett-Koehler, San Francisco. 